\title{
Risk Analysis on Refrigeration Unit by Approaching FMEA Model (A case study on fishing vessel)
}

\author{
${ }^{1}$ Muhamad Zaki Latif, ${ }^{1}$ Yuniar Endri Priharanto and ${ }^{2}$ Rahmad Surya Hadi Saputra \\ ${ }_{1}^{1}$ Marine and Fisheries Polytechnic of Sorong, Study Program of Fisheries Engineering, 98411 Sorong, West Papua, Indonesia. \\ ${ }^{2}$ Marine and Fisheries Polytechnic of Karawang, Study program of Capture Fisheries, 41315, Karawang, West Java, Indonesia.
}

Correspondence Author: Rahmad Surya Hadi Saputra. Marine and Fisheries Polytechnic Karawang, Study Program Capture Fisheries, 41315, Karawang, West Java, Indonesia.

$+6282113939224$

Received date: 22 December 2017, Accepted date: 22 January 2018, Online date: 5 February 2018

Copyright: (c) 2018 Muhamad Zaki Latif et al. This is an open-access article distributed under the terms of the Creative Commons Attribution License, which permits unrestricted use, distribution, and reproduction in any medium, provided the original author and source are credited.

\begin{abstract}
The existence of a refrigeration unit on a fishing vessel is necessary to maintain the quality of the capture. In operation, the refrigeration unit operates for 24 hours during fishing operations to ensure the quality of the catch is maintained. Fishing vessels utilize a refrigeration system to maintain the quality of catch by lowering the temperature of frozen storage space up to $-40{ }^{\circ} \mathrm{C}$. With a long period of operational conditions caused the reliability of its components to be reduced as time goes by the operation. Since refrigeration system is a very vital system in fishing vessel therefore appropriate maintenance measures are required to avoid system failure, reduce repair times if the failure is unavoidable and reduce risks to both refrigeration system products, systems and operators. This research will apply the use of FMEA to identify opportunities of failure on refrigeration unit on fishing vessel so as to reduce the risks and effects that occur in each mode of failure. This paper identifies the cause of failure and its effect on the refrigeration unit on board fishing vessel, furthermore, the risk analysis by scoring severity, occurrence, and detection till the critical part of the refrigeration unit can be discovered. Reduced frequency of failure or damage is always associated with precautions, while improving detection controls is an action aimed at limiting existing failures and is a temporary solution until precautions are made to address the problem. FMEA approach it can be known component of refrigeration that having highly risk and it causes. The cause of high risk occurs from the danger caused when the component in the refrigeration system fails, the high frequency failure mode and the lack of indicators that can give clues to the failure that will occur. In the mode of failure of leather seal in compressor have high severity level, but because of its emergence level is low and can be detected easily in case of failure mode hence yield conclusion of low value of RPN. Risk analysis on refrigeration unit on fishing vessel with FMEA approaches identified 4 critical components such as accumulator with RPN value 180, condenser with RPN value 144 and 128, evaporator with RPN value 135 and oil separator with RPN value 112.
\end{abstract}

Key words: Refrigeration unit, FMEA, operation and risk analysis

\section{INTRODUCTION}

Refrigeration serves to slow or withstand biological, physical and chemical changes in foodstuffs by lowering or maintaining a temperature below ambient temperature (Belenyi \& Gheorghe 2016). Fishing vessels utilize a refrigeration system to maintain the quality of catch by lowering the temperature of frozen storage space up to $-40{ }^{\circ} \mathrm{C}$.

The process occurring in the cooling system continues to recur from the process of compression of the refrigerant to the evaporation of the refrigerant. The process is carried out by compressors, condensers, valves (expansion valves) and evaporators where the structure of the components is similar on a cooling system. (Pedersen et al. 2017). On the refrigeration cycle refrigerants, mechanically its press by compressor thus the refrigerant flow to the condenser. In the condenser there is condensation process where the heat transferred to the environment. The refrigerant then flows to the expansion valve lowered its pressure and absorbs the heat of the environment through the evaporator then re-sucked by the compressor (Aste et al. 2017)

Maintenance of the refrigeration units to prevent any damage or when the damage occurs can be repaired with relatively short (Belenyi \& Gheorghe 2016) thus the product/ fish catch is not damaged due to malfunction of refrigeration system. there are four types of failure in the refrigeration system, among others, manufacturing failure, cooling failure, electrical failure and mechanical failure that can be minimized by performing maintenance (Belenyi \& Gheorghe 2016).

Maintenance planning for a system, it is necessary to identify the components in the system that can cause system failure, how the failure mode and what the consequences of failure. The failure analysis can be done using FMEA (Failure mode and effect analysis) which is one of the methods to prevent problems and identify the effects and solutions that can be given (Faturachman et al. 2014).

FMEA enables the team to design those failures out of the system with the minimum of effort and resource expenditure, thereby reducing development time and costs. It is widely used in manufacturing industries in various phases of the product life cycle and is now increasingly finding use in the service industry (Prajapati 2012).

The FMEA is a powerful design tool that provides a mean to compare, from a risk point of view, alternative machine system configurations. The FMEA is also useful for considering designs improvements for a technology which is changing or increasing in rating (Arabian-Hoseynabadi et al. 2010). Any FMEA 
should start with a flowchart that clearly defines the activity or function (design or process) to be analysed. Therefore, all the information on components in design or function or process must be collected (Puente et al. 2002).

Several studies have been done with the FMEA approach to identify problems and provide solutions, among others, the use of FMEA to prevent the risk of fire on diesel engines on board (Faturachman et al. 2014). The FMEA is a powerful design tool that provides a mean to compare, from a risk point of view, alternative machine system configurations. The FMEA is also useful for considering designs improvements for a technology which is changing or increasing in rating (Arabian-Hoseynabadi et al. 2010). FMEA can be explained as a group of events projected to (S. Parsana \& T. Patel 2014):

1. Recognize and evaluate the potential failure of a product or process and its effect;

2. Identify actions that could eliminate or reduce the chance of potential failures;

3. Document the process.

FMEA is a reliability tool, which requires identifying failure modes of a specific product or system, their frequency and potential causes. It is normally applied by an inter-functional work team, with the right know-how to analyze the whole product life cycle (Franceschini \& Galetto 2001). Failure-modes-andeffects Analysis (FMEA) has attracted some qualitative modeling work pursuing the goal of automating the task. FMEA, a mandatory task in the automotive and aeronautics industries, is performed by groups of experts during the design phase of a system (Struss \& Fraracci 2012).

In this paper FMEA is used to identify the cause of failure and its effect on refrigeration system in fishing vessel, then assess the risk using severity, Occurrence and detection to find the most critical part. The part with the highest risk value is categorized as the riskiest component so it is given a higher priority than the component having low risk value (Gupta et al. 2016).

Methods:

In constructing FMEA, a definition system was created based on the PID / Block diagram of the ship's installed refrigeration system. The PID / Block diagram is obtained by matching the PID with the instrument that has been installed on the ship to obtain a fit between the image and the installed components. In order to gather the valid data and assessed the level of severity, occurrence and detection will be done by interview to the chief engineer room and technicians who have more than 10 years' experience, as a result of a lack of written data on Indonesian fishing vessels regarding to the damage of components and its maintenance.

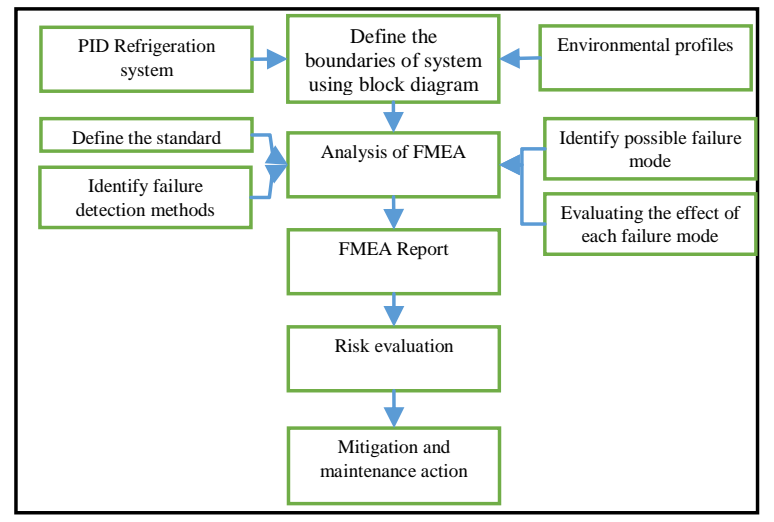

Fig. 1: Methods for FMEA approach

To facilitate assessing risk, failure modes are expressed on a scale of qualitative values that identify different levels of hazard conditions (Franceschini \& Galetto 2001). In the traditional FMEA approach, the RPN index is determined by calculating the product of the three indexes: severity, frequency and detection:

$\mathrm{RPN}=\mathrm{S} \times \mathrm{O} \times \mathrm{D}$

In the RPN calculation, the assigned values on the three index qualitative scales are interpreted as being numbers. 'Information initially gathered on the qualitative scales' is therefore arbitrarily interpreted and utilized on a quantitative scale with different properties from the first one (Franceschini \& Galetto 2001).

Severity is an assessment used to measure the importance of a failure mode. The scale of severity depends on the result of a failure on component performance. The severity level can be defined using the MTTR concept, low failure mode can be considered equal to low MTTR (Himam Saheb et al. 2016).

Tabel 1: Severity Scale

\begin{tabular}{ll}
\hline Severity & Description \\
\hline $1-2$ & probably not detect the failure \\
$3-4$ & Minor, low failure, not fully working, redundant appear \\
$5-6$ & Moderate, caused system unworked, maintenance relatively short, no redundant. \\
$7-8$ & High, Harmful to the system, caused the system down in period of time. \\
$9-10$ & Very dangerous, dangerous to the system and operator \\
\hline
\end{tabular}

\section{Occurrence:}

Occurrence is the frequency of an event that causes failure or can be called an opportunity of the emergence of a failure. Differences on the occurrence rate can be differentiated by helping the MTBF concept, if the time between each failure is relatively high, it can be said a high occurrence value (Himam Saheb et al. 2016).

Tabel 2: Occurence Scale

\begin{tabular}{ll}
\hline Occurrence & Description \\
\hline 1 & More than a year \\
3 & Between 4 to 6 months \\
5 & Between 1 to 3 months \\
7 & Every month \\
9 & Every time \\
\hline
\end{tabular}

\section{Detection:}

Detection is used to measure the probability of failure that can be detected either by control system or by manual inspection. In order to measure detection rates is highly subjective, according to the failure detection appearances (Himam Saheb et al. 2016). 
Tabel 3: Detection Scale

\begin{tabular}{|l|l|}
\hline Detection & Description \\
\hline 1 & Easily detected \\
\hline 3 & Detected by high probability \\
\hline 5 & Detected by moderate probability \\
\hline 7 & Detected by low probability \\
\hline 9 & Couldn't be detected \\
\hline
\end{tabular}

\section{Results:}

The early stages of FMEA drafting is done by making the boundary system using Reliability Block Diagram (RBD). To obtain the right boundary system is done by creating block diagrams based on PID refrigeration system installed on the vessel, then validated by conducting a field survey to ascertain whether the system installed on the ship is still in accordance with the document PID.

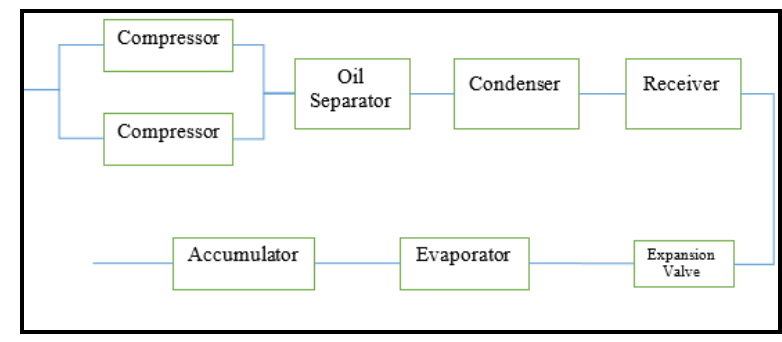

Fig. 2: System boundary by using Reliability Block Diagram

FMEA used as a tool to recognize the possibility failure arises before the failure occurs in order to reduce the risk by searching the priority cause and minimize the failure occurs (Feili et al. 2013).

A priority order as a result of RPN assessment can be used as a reference to implement the action. Furthermore, it can be done to Reduce the cause of failure, frequency or possibility of occurrence, and the severity that occurs due to the high possibility of increased detection (Puente $e t$ al. 2002).

Since the RPN value is calculated by using formula $\mathrm{RPN}=\mathrm{S} \times \mathrm{O} \times \mathrm{D}$, thus known as a component that require consideration. The failure mode that has the highest RPN value should be given priority in determining the precautions. This means that failure mode has the highest level of damage (severity) is not always given the highest priority, however it probably the priority has a low level of damage but has a high incidence frequency and can't be detected. These corrective actions may include special inspection, test or quality procedures, redesign (such as new component selection), redundancy addition and area limitation or operating period (Ambekar et al. 2013).

FMEA approaches is done in 7 (seven) components of refrigerant units which are compressor, oil separator, condenser, receiver, expansion valve, evaporator and accumulator. Analysis is covered to identify the potential failure causes, evaluated the effect of its failure and identify a detection failure mode. Moreover, this done by calculating on severity, occurrence and detection level for every single failure effect consequently achieve the RPN value based on the formula 1 (one).

Tabel 4: Failure Mode and Effect Analysis result

\begin{tabular}{|c|c|c|c|c|c|c|c|c|}
\hline Item & Function & $\begin{array}{l}\text { Potential failure } \\
\text { mode }\end{array}$ & $\begin{array}{l}\text { Potential effect(s) of } \\
\text { failure }\end{array}$ & failure detection method & $\mathrm{S}$ & $\mathrm{O}$ & $\mathrm{D}$ & RPN \\
\hline \multirow[t]{3}{*}{ Compressor } & \multirow[t]{3}{*}{$\begin{array}{l}\text { Compress the } \\
\text { refrigerant }\end{array}$} & Seal leaks & $\begin{array}{l}\text { Oil is reduce, Unit over } \\
\text { heat, Mechanical } \\
\text { compressor wears, Unit } \\
\text { locked or stop operation }\end{array}$ & Sight glass for oil level & 9 & 3 & 3 & 81 \\
\hline & & $\begin{array}{l}\text { Oil filter } \\
\text { blocked }\end{array}$ & $\begin{array}{l}\text { Oil circulation is low, } \\
\text { Unit heat, compressor } \\
\text { piston wears, unit locked } \\
\text { and Stopped }\end{array}$ & oil pressure gauge & 6 & 2 & 6 & 72 \\
\hline & & $\begin{array}{l}\text { filter suction } \\
\text { blocked }\end{array}$ & $\begin{array}{l}\text { Low suction pressure, low } \\
\text { suction pressure } \\
\text { compressor, Unit stop } \\
\text { working }\end{array}$ & No early warning & 5 & 2 & 1 & 10 \\
\hline \multirow[t]{2}{*}{ oil separator } & \multirow[t]{2}{*}{$\begin{array}{l}\text { Separated oil } \\
\text { flows within } \\
\text { refrigerant }\end{array}$} & $\begin{array}{l}\text { Dirt } \\
\text { separator }\end{array}$ & $\begin{array}{l}\text { Low oil in compressor, } \\
\text { Lubricant carried on the } \\
\text { system, compressor piston } \\
\text { wears, Less maximum } \\
\text { Freezing process } \\
\text { Compressor stop } \\
\text { working }\end{array}$ & sight glass for oil level & 7 & 4 & 4 & 112 \\
\hline & & Leak & $\begin{array}{l}\text { Oil remain low in } \\
\text { compressor, Unit heats, } \\
\text { piston compressor wears, } \\
\text { unit locked, stop working }\end{array}$ & sight glass for oil level & 9 & 2 & 2 & 36 \\
\hline \multirow[t]{3}{*}{ Condenser } & \multirow[t]{3}{*}{$\begin{array}{l}\text { Condensing } \\
\text { the } \\
\text { refrigerant }\end{array}$} & $\begin{array}{l}\text { filter on water is } \\
\text { plugged }\end{array}$ & $\begin{array}{l}\text { Water cooling is limited } \\
\text { flows, high discharge, } \\
\text { Compressor work hard, } \\
\text { overload, stopped work }\end{array}$ & high pressure gauge & 9 & 4 & 4 & 144 \\
\hline & & $\begin{array}{l}\text { Water } \\
\text { blocked } \\
\text { scaling }\end{array}$ & $\begin{array}{l}\text { Heat exchanger process } \\
\text { isn't optimal, high } \\
\text { discharge, Compressor } \\
\text { work hard, overload, } \\
\text { stopped work }\end{array}$ & high pressure gauge & 8 & 4 & 4 & 128 \\
\hline & & $\begin{array}{l}\text { Cooling pump } \\
\text { isn't working }\end{array}$ & $\begin{array}{l}\text { No heat exchanger } \\
\text { process overall, high } \\
\text { discharge, Compressor }\end{array}$ & visual & 9 & 3 & 2 & 54 \\
\hline
\end{tabular}


Citation: Muhamad Zaki Latif, Yuniar Endri Priharanto and Rahmad Surya Hadi Saputra, 2018. Risk Analysis on Refrigeration Unit by Approaching FMEA Model (A case study on fishing vessel). Australian Journal of Basic and Applied Sciences., 12(1): 22-27.

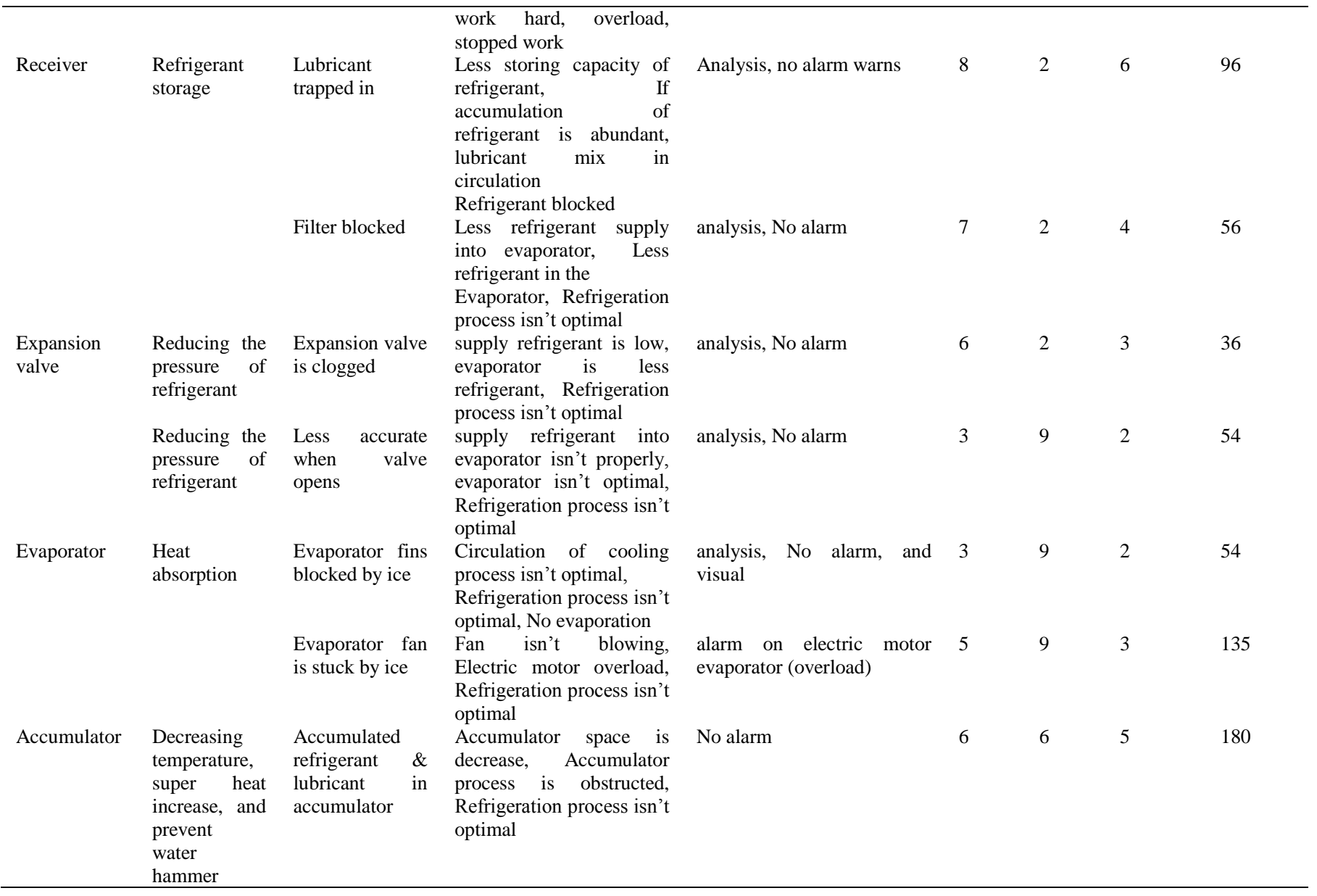

Assessments of S, O and D are assessed for each failure mode by specifying the appropriate severity due to failure, the occurrence rate associated with the probability of occurrence and the detection rate for each failure mode (Feili et al. 2013). Table 4 shows the values of S, O and D based on an expert's judgment according to the severity, occurrence and detection scale described in tables 1, 2 and 3 to produce the RPNs assessed using equation 1.

This RPN value is needed to evaluate the possible risks in the refrigeration component so that it can be identified components that require treatment measures. RPN values can be evaluated by recommendation to reduce severity, occurrence and detection factors (Salah et al. 2017) according to the characteristics of the failure mode of each component.

Based on table 4 . There are 4 components that have high RPN value such as accumulator, condenser, evaporator and oil separator.

\section{Discussion:}

FMEA Approach is done in order to identify the probability failure occurs. The failure assessed based on seriously on consequence, frequency of occurrence and ease of detection. (Salah et al. 2017). The result for FMEA approaches as shown in table 4 on the component of refrigeration units that has been achieve therefore projected as a graphic to ease on analysis the component which has the highest risk. Figure 3 shown the highest RPN on failure mode of accumulated lubricant in accumulator which has RPN value is 180 .

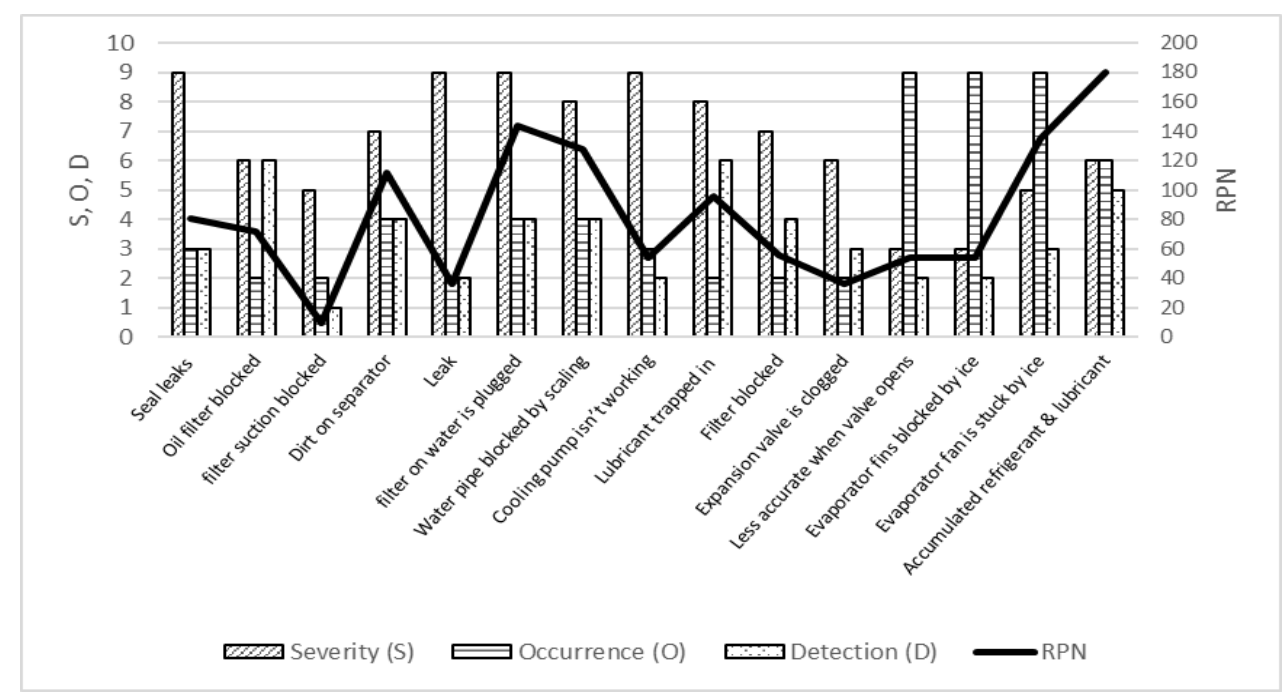

Fig. 3: RPN for each failure mode with S,O,D Scale 
Citation: Muhamad Zaki Latif, Yuniar Endri Priharanto and Rahmad Surya Hadi Saputra, 2018. Risk Analysis on Refrigeration Unit by Approaching FMEA Model (A case study on fishing vessel). Australian Journal of Basic and Applied Sciences., 12(1): 22-27.

The figure 3 describes some failure mode as follow seal leaks (compressor), leak (oil separator), cooling pump isn't working (condenser) which has the highest severity value, however this doesn't cause the component to have an excessively high risk as a result of the occurrence value is low and as well as easily detected if potential failure occurs.

Table 5 shown 4 (four) components which have the highest RPN where it has been ranked for knowing the components with failure modes that have the highest risk with the highest RPN value.

Tabel 5: Top 5 for highest RPN

\begin{tabular}{|c|c|c|c|c|c|c|}
\hline Rank & Item & failure mode & $\mathrm{S}$ & $\mathrm{O}$ & $\mathrm{D}$ & RPN \\
\hline 1 & Accumulator & Accumulated refrigerant \& lubricant in accumulator & 6 & 6 & 5 & 180 \\
\hline 2 & Condenser & filter on water is plugged & 9 & 4 & 4 & 144 \\
\hline 3 & Evaporator & Evaporator fan is stuck by ice & 5 & 9 & 3 & 135 \\
\hline 4 & Condenser & Water pipe blocked by scaling & 8 & 4 & 4 & 128 \\
\hline 5 & Oil Separator & Dirt on separator & 7 & 4 & 4 & 112 \\
\hline
\end{tabular}

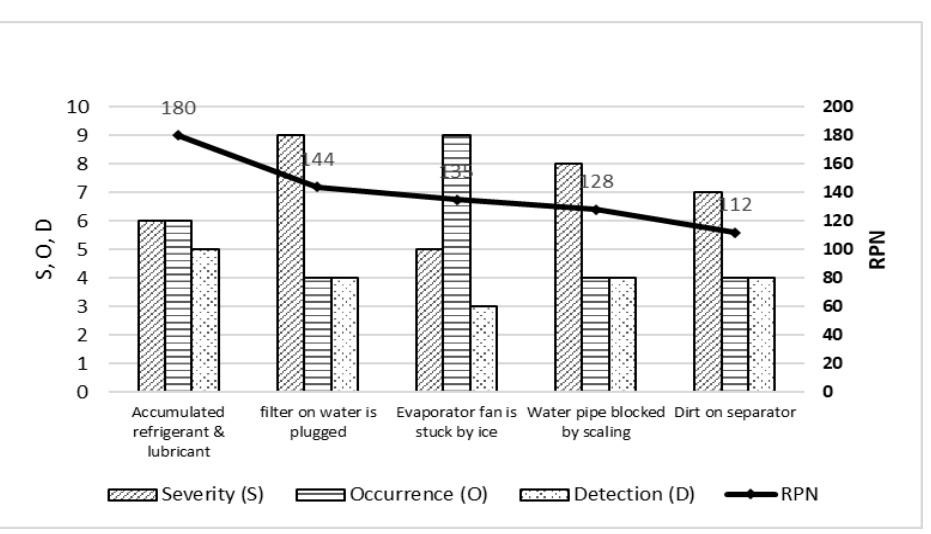

Fig. 4: Top 5 for highest RPN

Table 5 and figure 4 shown the highest number of RPN is 180 for failure modes of accumulated refrigerant and lubricant accumulator. This is because the severity level is 6 where in case of failure it will cause the system to be interrupted and there is no redundant, but it is also influenced by quite difficult to detect this failure mode with the detection level on the scale of 5.

The failure mode on the filter on water is clogged with the RPN value is 144 and it has detection level by 4 this mean it is easy enough to detect such failure and its low frequency occurrence on a scale of 4 . However, the RPN value becomes high due to the high severity of this failure mode because the condenser flows cooling material which has high pressure and temperature which must be cooled using cooling water thus the condensation process occurs. If the condensation process does not work very well then cause overheating on the condenser that affects the system and it can eventually cause the system to stop operating.

Mitigation efforts can be done by reducing the likelihood of occurrence and impact, can also doing risk transfer, avoid risk and accept the risks. Some mitigation efforts that can be done by setting a routine maintenance schedule, calling on workers to comply with SOPs, providing training, etc (Wessiani \& Sarwoko 2015)

This research purpose mitigation effort to decrease the level of risk can be done by reducing severity, occurrence, and detection as follow creating redundant, daily check, adding safety device or alarm. For accumulated refrigerant and lubricant in accumulator failure modes can be mitigated by lowering the detection level by installing a liquid alarm level that will be active if the liquid refrigerant / lubricant in the accumulator has reached the maximum limit. In addition, there may also be periodic expansion valve checks associated with expansion valve openings or replace with a thermostatic expansion valve to reduce the occurrence level.

Several alternative ways can be done for the failure mode of the filter on water is clogged by scheduling regular check and clean the cooling water filter and it is mainly done when the ship is not doing fishing activities. Furthermore, to reduce the risk can be added redundant to the filter on the condenser cooler.

Conclusion:

Refrigeration system is a very vital system in fishing vessels, because the refrigeration system on fishing vessel serves to maintain the quality of the catch during the vessel to conduct the fishing operation. Therefore, appropriate maintenance measures are required to avoid system failure, reduce repair times if the failure is unavoidable and reduce risks to both refrigeration system products, systems and operators.

FMEA approaches is used to identify the cause of the failure and its effect on the refrigeration system in the fishing vessel. the initial stage of FMEA is to establish a boundary system using a reliability block diagram to identify the components to be analyzed in the failure mode. The next stage using FMEA worksheet analysis of possible failure modes, the result of failure and the method to detect failure on the refrigeration component

Each failure mode is then assessed the level of severity, occurrence and detection to get the value of RPN. The greater RPN value's, the greater risk that can be caused by modes of failure component that may pose hazards to the system, operator, product or environment.

With FMEA approach it can be known component of refrigeration that having highly risk and it causes. The cause of high risk occurs from the danger caused when the component in the refrigeration system fails, the high frequency failure mode and the lack of indicators that can give clues to the failure that will occur. In the mode of failure of leather seal in compressor have high severity level, but because of its emergence level is low and can be detected easily in case of failure mode hence yield conclusion of low value of RPN.

Risk analysis on refrigeration unit on fishing vessel with FMEA approaches identified 4 critical components such as accumulator with RPN value 180, condenser with RPN value 144 and 128, evaporator with RPN value 135 and oil separator with RPN value 112. The RPN value was obtained from assessment of severity, occurrence and detection rates for each component with certain modes of failure.

The high value of RPN in the failure mode of accumulated refrigerant and lubricant in accumulator is due to the high S, O, D values at level 6 for the S and O values. The high $\mathrm{S}$ and $\mathrm{O}$ values can be reduced by taking precautions such as performing periodic checks, manual expansion due to accumulator refrigerant accumulation can be caused by the opening of the expansion valve that is too large so that not all the coolant evaporates in the evaporator causing the accumulation in the evaporator. In addition, prevention can also be done by cleaning the ice flower in evaporator periodically. The accumulation of ice flower in the evaporator can inhibit the heat absorption of the product by the refrigerant thus causing the refrigerant not entirely to evaporate in the evaporator causing accumulated refrigerant accumulator.

In the failure mode of the filter on water plugged in the condenser with the value of RPN 144 caused by the high severity value of 9 . This failure mode causes the coolant pressure in the condenser to be too high due to failure in the condensation process this can cause severe condenser damage and can result in further damage to the compressor. The work that can be done to reduce the RPN value in this mode of failure is to reduce the severity. The work that can be done 
is to add a safety valve in the condenser. Broadly speaking, efforts to reduce risks to the refrigeration system are done by reducing the severity, reducing the rate of occurrence and can be detected easily. by knowing the level of risk on a system then it can determine precise and efficient failure precautions.

Future work:

in the future further analysis can be done by combining FMEA and other expert assessment methods such as AHP (Analytical hierarchy process) to obtain conformance in terms of components that are critical components of FMEA and AHP analysis to improve accuracy in providing recommendations for system improvement or maintenance measures that should do. The results of FMEA analysis and other assessments can be used as reference in determining the scheduling of refrigeration system maintenance by synchronizing between the maintenance time and the operational time of the fishing vessel. This can be done to improve the reliability of the cooling system in an effort to streamline operational costs and reduce maintenance costs due to failure of the system.

\section{REFERENCES}

Ambekar, S.B., A. Edlabadkar and V. Shrouty, 2013. A Review : Implementation of Failure Mode and Effect Analysis. International Journal of Engineering and Innovative Technology, 2(8): 37-41.

Arabian-Hoseynabadi, H., H. Oraee and P.J. Tavner, 2010. Failure Modes and Effects Analysis (FMEA) for wind turbines. International Journal of Electrical Power and Energy Systems, 32(7): 817-824.

Aste, N., C. Del Pero and F. Leonforte, 2017. Active refrigeration technologies for food preservation in humanitarian context - A review. Sustainable Energy Technologies and Assessments, 22: 150-160.

Belenyi, A. and A. Gheorghe, 2016. Studies and Research on Maintenance of Refrigeration Equipment. Applied Mathmatics, Mechanics, and Engineering, 59(3): 303-308

Faturachman, D. et al., 2014. Failure mode and effects analysis of diesel engine for ship navigation system improvement. International Journal of Service Science, Management and Engineering, 1(1): 6-16.

Feili, H.R. et al., 2013. Risk analysis of geothermal power plants using Failure Modes and Effects Analysis (FMEA) technique. Energy Conversion and Management, 72: 69-76.

Franceschini, F. and M. Galetto, 2001. A New Approach for Evaluation of Risk Priorities of Failure Modes in FMEA. International Journal of Production Research, 39(13): 2991-3002.

Gupta, G., R.P. Mishra and P. Singhvi, 2016. An Application of Reliability Centered Maintenance Using RPN Mean and Range on Conventional Lathe Machine. International Journal of Reliability, Quality and Safety Engineering, 23(6): 1640010 (10 pages). Available at: http://www.worldscientific.com/doi/abs/10.1142/S0218539316400106.

Himam Saheb, S., V.K. Annam and Y. Avula, 2016. DFMEA of a Roller Mill Gear box. International Journal Of Advancement In Engineering Technology, 3(7): 83-90. Available at: www.ijaetmas.com.

Pedersen, T.S. et al., 2017. Predictive Functional Control of Superheat in a Refrigeration System using a Neural Network Model. IFAC-PapersOnLine, 50(1): 43-48. Available at: https://doi.org/10.1016/j.ifacol.2017.08.008.

Prajapati, D.R., 2012. Implementation of Failure Mode and Effect Analysis:A Literature Review. Ijmie, 2(7): 264-292.

Puente, J. et al., 2002. A decision support system for applying failure mode and effects analysis. International Journal of Quality \& Reliability Management, 19(2): 137-150.

Parsana, S.T. and T. M. Patel, 2014. A Case Study: A Process FMEA Tool to Enhance Quality and Efficiency of Manufacturing Industry. Bonfring International Journal of Industrial Engineering and Management Science., 4(3): 145-152.

Salah, B., M. Alkahtani and A. Ziout, 2017. Using FMEA analysis for assessing air conditioners remanufacturing processes. In Proceedings of the International Conference on Industrial Engineering and Operations Management, pp: 2431-2437.

Struss, P. and A. Fraracci, 2012. Automated model-based FMEA of a braking system, IFAC.

Wessiani, N.A. and S.O. Sarwoko, 2015. Risk analysis of poultry feed production using fuzzy FMEA. Procedia Manufacturing, 4: 270-281.

\section{Highlights and contributions}

$>\quad$ The efficiency of fishing operations cost especially to the fishing vessel with size 25 GT - 30 GT in Indonesia.

$>$ Minimize maintenance cost of refrigeration unit on board since this system is very important to keep the quality of fish.

$>$ Giving information to all operator of refrigeration unit around the world to concern about preventive maintenance. 